OPEN ACCESS

Edited by:

Kim Nguyen,

Indiana University, Purdue University Indianapolis, United States

Reviewed by:

Derrick L Tillman-Kelly, The Ohio State University, United States

Randall Roper,

Indiana University, Purdue University Indianapolis, United States

Tabitha Hardy,

Indiana University, Purdue University Indianapolis, United States

${ }^{*}$ Correspondence:

Demetri L. Morgan

demetrimorganphd@outlook.com

Specialty section:

This article was submitted to

STEM Education,

a section of the journal

Frontiers in Education

Received: 16 February 2021

Accepted: 23 July 2021

Published: 13 August 2021

Citation:

Morgan DL, Callais VE, Acevedo Mand Davis KB (2021) A Potential Canary in the Coal Mine: A Critical Policy Analysis of the Illinois LSAMP During the COVID-19 Pandemic.

Front. Educ. 6:668394.

doi: 10.3389/feduc.2021.668394

\section{A Potential Canary in the Coal Mine: A Critical Policy Analysis of the Illinois LSAMP During the COVID-19 Pandemic}

\author{
Demetri L. Morgan ${ }^{1 *}$, Victoria E. Callais ${ }^{1}$, Maria Acevedo ${ }^{2}$ and Kendrick B. Davis ${ }^{3}$ \\ ${ }^{1}$ Higher Education Program, School of Education, Loyola University Chicago, Chicago, IL, United States, ${ }^{2}$ Department of Physics, \\ Trinity College of Arts and Sciences, Duke University, Durham, NC, United States, ${ }^{3}$ Race and Equity Center, University of Southern \\ California, Los Angeles, CA, United States
}

The COVID-19 pandemic has continued to impact every industry and test problem-solving capabilities and innovation across the board; education is no exception. As institutions continue to adapt to the impacts of the current public health crisis, colleges and universities are also navigating federal policy prompted by the pandemic. Literature has shown the positive influence of organizations, such as the Louis Stokes Alliances for Minority Participation (LSAMP), and, we argue that they can take a more active intermediary approach, that of an Organizational Buffer, to best support their students during times of uncertainty. Current research highlights the disconnect between STEM education and policy, as well as how the pandemic is disproportionately impacting communities of color. The pervasiveness of whiteness within educational policy and the negative impacts of unequal distribution of resources on students of color in STEM highlight the need to center race in a theoretical framework and policy. The purpose of this study was to understand the policy and communication responses to the pandemic as they pertained to supporting student success in STEM. Using the Theory of Racialized Organizations, which is a qualitative case study approach that leverages diffractive readings, was implemented to understand whether educational policy and communication responses during this time have or perpetuated inequitable systems. Guided by the research question, in what ways do pandemic policies and communications bolster the success of underrepresented minoritized students (URM) majoring in STEM, our study found four versions of policymaking (i.e., Performative, Picking Winners and Losers, Stay in your Lane, and Time Burden) that emerged and did not support URM STEM students equitably and consistently. Based on these findings, we present implications for institutional responses, LSAMP-alliance support, and future research.

Keywords: stem education, organizational theory, race, equity, student success, critical policy analysis 


\section{INTRODUCTION}

Since the Louis Stokes Alliances for Minority Participation's (LSAMP) founding in 1991 (Clewell et al., 2006; Baber and Jackson, 2018), there have been numerous focusing events Kingdon (2013) that bring specific issues to the fore of consciousness for policymakers and the public. As a result, these focusing events, when narrowed to particular fields and industries, such as science, technology, engineering, and mathematics (STEM), enable rapid and sweeping changes in how relevant dynamics (e.g., technical skills, accreditation standards, ethical norms, etc.) are taught and performed in both postsecondary education and industry spaces (Henderson et al., 2011; Gruber and Johnson, 2019). For instance, in the 1990s, the rise of Silicon Valley harkened dialogues about the best ways to regulate the emergence of the world wide web Norris and Inglehart (2009) and how to diversify the population of individuals involved in the growing technology space (Twine, 2018). Another example of a focusing event intersecting with STEM emerged after the September 11, 2001 attacks on the World Trade Center in New York. Immigration policies changed, which affected the flow of skilled laborers in STEM professions Kennedy (2019) and had resulting impacts by heightened the need for a greater share of US-born individuals to fill open positions (Orrenius and Zavodny, 2015).

\section{Purpose}

Yet, during these sweeping events and subsequent policy actions, there are rarely efforts to take stock of the evolving policy environment and analyze dimensions embedded in the policymaking process as a crisis unfolds, especially within the STEM education literature. Consequently, the purpose of this paper is to understand the focusing event of the COVID-19 pandemic and its resulting policies and how they intersected with enablers of student success in STEM education through the lens of institutions affiliated with the Illinois LSAMP (IL-LSAMP) (see Table 1). Birkland (1998) describes focusing events as occurrences that are:

sudden; relatively uncommon; can be reasonably defined as harmful or revealing the possibility of potentially more significant future harms; has harms that are concentrated in a particular geographical area or community of interest; and that is known to policymakers and the public simultaneously. (p. 55).

The COVID-19 pandemic fits such a description and provides the departure point for our study. The concept of focusing events flows from Kingdon's (2013) assessment of the policymaking process and agenda-setting in particular. In Kingdon's (2013) articulation, focusing events galvanize the interest and support of a coalition of policymakers who are newly coupled together to move the policymaking process along in a way that addresses both new and pre-existing issues. As the next section will bear out, it is not typical to study STEM education from the policymaking process's vantage point. However, STEM education is impacted both directly and indirectly by the policymaking process at institutional, local, state, and federal levels (Ong et al., 2011). Consequently, the ongoing nature of the COVID-19 pandemic and the series of "stimulus" bills passed by Congress beginning in
March 2020 frame a unique opportunity to examine policy formation and implementation occurring together over a relatively brief period (Hillman et al., 2015).

Furthermore, the documented racial disparities across health, economics, and education that have only been worsened by the pandemic prompt us to foreground an analytical strategy that heightens our ability to locate racial dynamics in the policy process and within organizations (Harper, 2010; Young and Diem, 2018; Ray, 2019). Finally, it is essential to note the specific impetus for this study, which was as an Alliance wide conference call the research team members participated in during May of 2020. We listened along, feeling helpless as our colleagues grappled with how to carry on the Alliance's work while addressing their other work responsibilities and surviving a pandemic. While there was a collective sense of relief as the summer approached, there was also a sense of dread as many of the activities planned for the summer across the Alliance were either being canceled or postponed.

Knowing the already limited capacities and resources for the people who make the Alliance what it is and the pandemicinduced struggles of its member institutions, we quickly turned our attention to the various policies designed and implemented to support students' success and institutions as a whole through the pandemic. We contend that the Alliance is a uniquely positioned National Science Foundation. (NSF) program because it has a governing board made up of all its constituent institutions' chancellor or president. In a pandemic, where the STEM ecosystem's prospects for equitable success were most vulnerable, we hoped that the Alliance could rally the collective insights and leadership of all of its essential elements to navigate through the situation. Only time will tell the full extent of the early parts of the pandemic on the Alliance and the prospect of its underrepresented minoritized ${ }^{1}$ (URM) STEM students, but what felt like an exercise that could be addressed more immediately was the extent to which the policies and communications amid the pandemic even sought to address student success in STEM with an eye towards equity. By equity focus, we mean devoting the requisite level of resources at all levels of the institution to ensure minoritized groups have opportunities and support to realize their educational outcomes and exhibit the fullest extent of their agency and talents $(\mathrm{McNair}$ et al., 2019; Rall et al., 2020).

\section{General Approach and Research Question}

We leverage a case study approach that utilizes a policy analysis tool of diffractive readings Ulmer (2016) to explore educational policy and communication responses to the pandemic. In particular, we center the role of organizations in legitimizing or disrupting systems of inequity around race, regardless of the

\footnotetext{
${ }^{1}$ We use the term "minoritized" rather than minority in concurrence with Harper's (2010) call to bring attention to the interaction of oppressive forces within organizations that render minority status on certain groups due to their incongruence with the prevailing norms of the space. This term also acknowledges that people who are considered "minorities" or "underrepresented" are not always numerically in the minority, as was the case with this project.
} 
TABLE 1 | IL-LSAMP institution characteristics.

\begin{tabular}{|c|c|c|c|c|}
\hline Institution name & Governance/control & $\begin{array}{l}\text { Overall completion rate } \\
\text { for URM STEM } \\
\text { students }(\%)\end{array}$ & $\begin{array}{c}\text { Number } \\
\text { of STEM programs }\end{array}$ & $\begin{array}{l}\text { CARES Act emergency } \\
\text { funding (minimum allocation } \\
\text { for student aid) }\end{array}$ \\
\hline Chicago State University & 4-year public & 3.40 & 5 & $\$ 1,086,007$ \\
\hline DePaul University & 4-year private & 2.96 & 17 & $\$ 7,186,610$ \\
\hline Governors State University & 4-year public & 4.77 & 5 & $\$ 1,851,301$ \\
\hline Illinois Institute of Technology & 4-year private & 16.17 & 28 & $\$ 1,865,000$ \\
\hline Malcolm X College & 2-year public & 15.42 & 3 & $\$ 2,459,879$ \\
\hline Morton College & 2-year public & 19.27 & 5 & $\$ 1,266,322$ \\
\hline Northeastern Illinois University & 4-year public & 5.44 & 11 & $\$ 3,035,452$ \\
\hline Prairie State College & 4-year public & 9.96 & 5 & $\$ 1,261,894$ \\
\hline Southern Illinois University, Edwardsville & 4-year public & 1.84 & 13 & $\$ 4,893,197$ \\
\hline St. Augustine College & 4-year private & 3.40 & 1 & $\$ 748,491$ \\
\hline University of Illinois, Chicago & 4-year public & 8.32 & 21 & $\$ 14,937,295$ \\
\hline University of Illinois, Springfield & 4-year public & 3.97 & 7 & $\$ 865,944$ \\
\hline
\end{tabular}

Note:

*We take URM to represent: American Indian and Alaska Native, Black or African American, Hispanic/Latino, and Native Hawaiian or other Pacific Islander.

*We take STEM to be programs of study in engineering and engineering technology, the biological and biomedical sciences, computer and information sciences, health professions, mathematics and statistics, and physical and life sciences.

*We take undergraduate to mean associates and bachelor's degrees where appropriate.

racial equity values espoused in official pandemic-related communication and documentation. The question that oriented our exploration was: In what ways do pandemic policies and communications bolster the success of underrepresented minoritized students (URM) majoring in STEM?

\section{Imbalance in the Ecosystem: Disrupting Progress in STEM Education}

Journalists, academics, policymakers, and the broader public are in widescale agreement that no industry has been left undisturbed by the COVID-19 pandemic (Kushner Gadarian et al., 2020). Yet, many argue that the education sector has been hit particularly hard because of the shift to wide-scale remote learning (Collier et al., 2021). In addition, at the postsecondary education level, the disparate ways institutions have chosen to respond to the pandemic has led to an array of approaches that all have nuanced impacts on students that we are only beginning to understand (e.g., Collier et al., 2020; Marsicano et al., 2020; Whatley and Castiello-Gutiérrez, 2021); further, higher education budgets are often the first victims of tightening state budgets. Importantly, researchers are making initial cases that remote learning during the pandemic has an exaggerated negative effect on STEM instruction and STEM students' performance (McCormick, 2021). This emerging reality also dovetails with the disruption of the momentum in the last 10 years to shift STEM pedagogy to be more participatory and collaborative (Henderson et al., 2011; Dewsbury, 2020). These dynamics and others have led educational leaders to opine about the extent to which the pandemic is only furthering pre-existing worries about equity and persistence in STEM for URM student populations (Goodwin \& Mitchneck, 2020; Woolston, 2020). Bolstering the STEM education enterprise will ensure the entire system's longevity and viability; no component of the policy ecosystem can be ignored.

\section{Torques and Tensions: The Political Dynamics of Science and Policy}

These realities set the context for policymakers and administrators' intentional actions to address the emergent and underlying issues through policy. Although the BidenHarris Administration The White House (2021) has made early efforts to be more deliberate about connecting science and policymaking, that is a relatively recent development. Since the Cold War days, there has been a tenuous relationship between policy and science (Gruber and Johnson, 2019). The precarious relationship between the entities and concepts is rooted in the partisan realities that policymakers must navigate to stay in elected office (Bolsen and Druckman, 2018). These tensions differ from the occasionally disengaged posture individuals in the STEM community embrace, which is rooted in an effort to seem above or disconnected from the political fray (Nature Editorial Board, 2020). The impact of this bumpy relationship spreads into the realities of its constituent parts, such as STEM education and the policies that directly and indirectly impact student success in postsecondary education. Therefore, our literature review seeks to further situate our exploration on this topic alongside existing knowledge of policy, STEM education, whiteness, and organizational responses.

\section{LITERATURE REVIEW: CREATING "THICK UNDERSTANDINGS"}

This literature review aims to build for ourselves and the reader what Murris and Bozalek (2019) describe as "thick understandings" of the area of exploration. Thick understandings are created by "re-turning to the past [literature on the topic]" with an intent to frame points of engagement with existing understandings of life rather than to review, critique, and set aside (Murris and Bozalek, 2019, 
p. 1512). Consequently, our exploration begins first by examining the disconnect between STEM education research and policy. We contend that strengthening the connection between these two domains is beneficial for STEM education research and practice. Next, since research has shown the pandemic has disproportionately impacted communities of color (DeMatthews et al., 2020; Fortuna et al., 2020), we highlight the pervasiveness of whiteness within educational policy. Making this connection felt especially prudent to crafting a thick understanding of our topic because of the harmful impacts of unequal distribution of resources on students of color within STEM-spurring the need to center race in policy language. Lastly, we focus on LSAMP organizations and the intermediary functions (Honig, 2004) they can take advantage of in times of uncertainty to best serve their constituents by examining the current roles research has asserted they play. Together, these points scaffold us toward the understanding that STEM education and policy likely become intertwined within organizations, like postsecondary institutions and arguably LSAMP, in ways that are far more complex than typically acknowledged in the literature.

\section{Gap Analysis: Public Policy and STEM Education}

STEM education research, similar to science research more broadly, is often disjointed from the policy context it is situated within (Kezar and Holcombe, 2019; Nature Editorial Board, 2020). The disconnect is potentially harmful to students and institutions for reasons including securing and maintaining funding (Fischhoff and Scheufele, 2014), ensuring stakeholder priorities are aligned, and the need for current and future research (The National Academies of Science Engineering Medicine, 2017). NSF contributes to a significant portion of funding that supports STEM education. Although contested (Roberts, 2009), the reasoning for this continued support of STEM education is based on the perception that the U.S. STEM workforce will decline significantly in the future, putting the national standing in jeopardy and there needs to be a concentrated effort to support and produce STEM graduates (Mansfield et al., 2014; Doerschuk et al., 2016; Gruber and Johnson, 2019; Lord et al., 2019). Therefore, STEM education research that does not consider the policy context potentially puts the STEM education enterprise at risk, financially and institutionally, if not continually positioning the enterprise as a public asset to the nation. Accordingly, an awareness of the narratives and current events taking place that deem STEM education as essential or not is vital as is locating it within the agendasetting Kingdon (2013) and policymaking process (Hillman et al., 2015).

\section{Message Diffusion: Policy Communication}

In addition to federal funding and policies that impact STEM education and research, the application and communication of policies at an institutional level is a distinct but related consideration (Ness, 2010; Faehnrich and Ruser, 2019). Anderson (2012) investigated how policy, specifically test- based accountability policies, influences practice at the school level. Anderson (2012) concluded that policymakers must consider how educators make sense of the new or adjusted policies in order to avoid the educator's feeling unnecesairly constrained in their instructional methods. This is corroborated in additional studies of faculty and staff members involved in STEM organizational change (Gehrke and Kezar, 2017; Bensimon et al., 2019; Park et al., 2020). However, these studies do not foreground a concern for public policymaking. In the public policy domain, Spillane and Callahan (2000) highlighted a revealing case of a district change effort around STEM within primary and secondary education. They found that when district policymakers do not understand the vision or purpose of ideas that can reform or better support STEM education (i.e., science standards), it is difficult for the implementation to align with the original intent (Spillane and Callahan, 2000).

\section{Forced Evolution: Re-Evaluating Policy Priorities}

It is essential to acknowledge the varied support and resources different populations of STEM students need to advocate for policy that addresses these needs (Harper, 2010; McGee, 2016; Ong et al., 2011; Garibay, 2018; Ong et al., 2018). If STEM education researchers continue to be detached from the policy process, then there is concern that change may remain limited to individuals and networks' capacities and inputs (Gehrke and Kezar, 2017; Hill, 2020). In contrast, much has been gained in the areas of college access (Harper et al., 2009; Hillman, 2016; González Canché, 2018), institutional funding Jones et al. (2017), Gándara (2020), and improving campus climates (Glasener et al., 2019; LePeau et al., 2019) when their intersection with policies are foregrounded as an issue of interest for researchers. Therefore, it is crucial for STEM education research to be more aware of, and engaged with, policymaking and policy implementation to better support and retain students.

\section{Pre-Determined Realities: Educational Policy and the Construct of Whiteness}

In considering how to best support URM STEM students during a pandemic, we turn next to how students continue to navigate an inequitable system and unequal support structures that are in place. Research has shown the negative impact and unintended consequences that occur when resources are distributed inequitably within education particularly for racially and ethnically minoritized students (Harper, 2010; Ong et al., 2011; Burt et al., 2020). Specifically, when resources are not allocated fairly and equitably this enables the following factors to persist which contributes to URM STEM students being less likely to be retained and complete their degrees: graduating from low-resourced high schools (Means et al., 2018; Glennie et al., 2019; Morales-Doyle et al., 2019), experiencing racial stereotypes and racism in college classrooms (McGee, 2016; McGee, 2018); being the only or one of a few students from one's racial group in STEM courses (Ireland et al., 2018; Ong et al., 2018); having 
minimal or no exposure to professors of color in STEM majors (Hurtado et al., 2011; McCoy et al., 2017; Park et al., 2020); ineffective teaching and mentoring (Bensimon et al., 2019; Haynes and Patton, 2019; Dewsbury, 2020); and culturally unresponsive or decontextualized curricula (Bullock, 2017; Wolfmeyer et al., 2017; Madkins and Nasir, 2019). These racialized realities from the vantage point of STEM are often not considered in educational policy which further supports the inequitable distribution to persist.

On the other hand, educational policy research is often presented as neutral and intended to be fair in its application, regardless of racialized realities (Diem et al., 2014; Tichavakunda, 2020). Research continues to indicate that this presentation is not realistic and that policy cannot be applied in a one size fits all approach due to the complexity and the persistence of intersecting oppressive systems and ideologies in the United States (e.g., systemic racism, sexism, ableism, heteronormativity, etc.) (Gillborn, 2005; Diem et al., 2014; Johnson and Howley, 2015; Harris and Patton, 2018). The cause of this neutrality in policy has been connected to the pervasiveness of whiteness within education (Gillborn, 2005; Diem et al., 2014). Whiteness is a social construct that functions to reinscribe white supremacy and the subordination of non-white races, across different contexts, within a society (Owen, 2007).

Research in other areas of higher education that center on whiteness have shown the pernicious effects for multiple stakeholders which include a lower sense of safety on campus, less sense of belonging, and decreased academic performance (Cabrera, 2014; LePeau et al., 2016; Stewart and Nicolazzo, 2018; Haynes and Patton, 2019). Extended into the policy realm, education scholars have begun to unearth how whiteness exists in various ways within the education system and policy (e.g., segregation, testing, funding, unequal resources, etc.) Gillborn (2005), Harper et al. (2009) and continues to exist within colorblind approaches and language (Harper, 2012; Tichavakunda, 2020). Therefore, any exploration into educational policy must be explicitly attuned to the dynamics of whiteness and the sites where those dynamics play out.

\section{A New Frontier?: LSAMP During Times of Crisis}

The LSAMP program began to better support the retention and completion of URM STEM students and encourage them to pursue STEM-related roles after receiving their baccalaureate degree (Clewell et al., 2006; Cox et al., 2012; Baber and Jackson, 2018). Concerns for the longevity of the United States STEM workforce, the projected decline of United States STEM graduates, and other fears (e.g., drop in productivity, international competitiveness) led the NSF (n.d.) to prioritize efforts to support the retention of URM students, who are traditionally underrepresented, in STEM through initiatives like LSAMP for over 2 decades. LSAMP includes multiinstitutional collaboration through alliances that provide students with academic support, mentorship, research opportunities, and in some cases, funding. Programming through LSAMP is supported through grant funding. Research has shown that LSAMP are beneficial and effective for URM STEM students when the programming does not have to navigate policy or legal restraints (e.g., Hopwood Decision) (Graham et al., 2002).

Although the strengths and weaknesses of LSAMP vary by state and is dependent on the campuses they are located on (Baber and Jackson, 2018), the programming is considered beneficial for the URM STEM students as well as the institutions involved (Graham et al., 2002; Cox et al., 2012; King et al., 2016; Burt et al., 2020). However, these studies of LSAMP may not be fully reflective of programming during a time of crisis or policy influences on outcomes. Nevertheless, due to the intimate relationship this programming has with URM STEM students, it can anticipate the needs of these students if a crisis does occur and address their needs in a timely and efficient manner through multiple levels of intervention. The levels of potential intervention include peer supports (Ong et al., 2018), faculty mentoring (Gehrke and Kezar, 2017; McCoy et al., 2017), staff advising (Bensimon et al., 2019), and institutional leadership (Kezar, 2011). This reality invokes the need to situate better the role of policy Hillman et al. (2015) and strategic communication (Faehnrich and Ruser, 2019), which can serve as external mechanisms to spur organizational change to support students (Kezar and Holcombe, 2019).

\section{In/Conclusion}

The impact of the COVID-19 pandemic will continue to become more well-defined as time goes on. As the literature has depicted in STEM education, pre-existing disparities and dynamics will be exacerbated by the pandemic. Therefore, institutions and policymakers need to be aware of the array of potential realities to be proactive in their approaches to mediate inequities. Although there is more research needed on organizational change and STEM education and policy in a crisis, there are resources and programming that currently exist that can be used to better support students. LSAMP programming, which is already funded and in place, can play a more active intermediary role Honig (2004) between their campus community and policy that is affecting their institutions. In addition to reframing how to use programming to better support URM STEM students, there is a need for STEM education to understand how it is situated within policy and how to strengthen that relationship (e.g., creation, implementation, understanding) in order to be prepared and equipped in a time of crisis and beyond (Hillman et al., 2015).

\section{THEORETICAL FRAMEWORK}

As our review of the literature highlights, the intersection of public policy, the experiences of racially minoritized individuals, and STEM education is primed for an investigation that can yield novel insights. These domains' confluence often manifests in organizations such as postsecondary education institutions or a collection of organizations such as the LSAMP. As entities such as these continue to grapple with how to address persistent 
challenges related to the access and success of URMs in STEM amid and following the pandemic, the prevailing question becomes how to carry out their practices and policies in ways that do not reify deficit-laden descriptions of students of color Harper (2010), McGee (2016) and constrain their educational potential (Garibay, 2018). The weight of this lofty effort is compounded by the dearth of research at this intersection, which also means that few theories can be intentionally leveraged to frame these organizational dynamics. Therefore, we turn to the discipline of sociology and the theory of racialized organizations Ray (2019) to highlight relevant dimensions of interest for our diffractive policy analysis (Ulmer, 2016).

\section{Ray's Theory of Racialized Organizations}

Ray (2019) developed the theory of racialized organizations because of their simultaneous critique that race issues are often omitted from organizational analysis and race theory is often devoid of organizations as a site of analysis. Said another way, when STEM education scholars are concerned with organizations, they tend to privilege the investigation of other issues (e.g., graduation, technical skill development, etc.) over racialized concerns (Porter et al., 2006; Gehrke and Kezar, 2017; Reinholz and Apkarian, 2018). Conversely, as numerous studies call out (McGee, 2016; Bullock, 2017; Ong et al., 2018), STEM education research tends to shy away from naming issues of race as an explanatory mechanism in their analysis.

\section{Definitionand Three Core Tenets}

Ray (2019) defines racialized organizations as: meso-level social structures that limit the personal agency and collective efficacy of subordinate racial groups while magnifying the dominant racial group's agency. The ability to act upon the world, to create, to learn, to express emotion,-indeed, one's full humanity is constrained (or enabled) by racialized organizations. (p. 36).

Ray (2019) suggests that organizations mediate human agency on a spectrum of three core components: 1) the unequal distribution of resources, 2) the credentialing of Whiteness, and 3) racialized decoupling. We briefly overview each of the components of the theory of racialized organizations and revisit them in the findings section to pair with our data.

\section{Unequal Distribution of Resources}

This tenet refers to the historical and contemporary manifestation of segregation within organizations that helps to "maintain racial boundaries, channel resources, and help direct collective action” (Ray, 2019).

\section{Credentialing of Whiteness}

This tenet builds on the assertion of Whiteness as a form of property interest (Harris, 1993). Ray (2019) argues that Whiteness has become the de facto mechanism for allocating resources within organizations and reinforces work hierarchies. Thus, creating policies to address STEM education remains mindful of the cumulative advantages some students may have over others because of how organizations typically enable advantages to be accrued based on their proximity to Whiteness.

\section{Racialized Decoupling}

Finally, Ray (2019) alerts us to the concept of racialized decoupling in organizations. Racialized decoupling is the process of disentangling "formal commitments to equity, access, and inclusion from policies and practices that reinforce, or at least do not challenge, existing racial hierarchies" (p. 42). This tenet is particularly relevant to our analysis because it identifies practices that embolden organizations to perpetuate structures and the unequal distribution of resources while doing very little to disrupt or transform entrenched racial dynamics. Taken together then, the theory of racialized organizations is appropriate framing for our study because it focuses on how Whiteness operates within organizations in ways that are hard to detect. Especially given our effort to map the intersection of public policy on STEM education with a racialized focus, these tenets are especially germane. Also, it is important to us that our analysis be concerned with ultimately making policy and practice recommendations focused on addressing inequity dimensions. Lastly, as the next section will detail, the theory is critical to crafting and operationalizing our research design around diffractive readings and critical policy analysis (Ulmer, 2016).

\section{RESEARCH DESIGN}

Our overall approach was driven by critical policy analysis (CPA) Diem et al. (2014), Apple (2019) and operationalized through the specific method of diffractive reading. In response to this paradigm of policy studies, critical policy analysis has emerged as an approach that is more imaginative and moldable to different purposes, especially in education research (Ulmer, 2016; Young and Diem, 2018) (Ulmer, 2016; Young and Diem, 2018). This process is illustrated in Figure 1 and described below.

\section{Critical Policy Analysis}

Critical policy analysis in education research tends to deal with one or more of five fundamental concerns. These include: 1) the gap between "policy rhetoric and practiced reality;" 2) policy development; 3) "distribution of power, resources, and knowledge and the creation of "winners" and "losers" ;"4) social stratification; and 5) engagement and resistance of "non-dominant" groups in policies (Diem et al., 2014, p. 1072). Further, critical policy analysis projects tend to seek to capture the full complexity of policy processes (Diem et al., 2014; Young and Diem, 2018). This includes contextualizing the differential impact of policies, the diverse actors connected to the policy, and how policies evolve. Our study spans the federal, state, local, and institutional domains to understand how pandemic policies converge on institutions to compel differential impacts between URM and non-URM STEM students. 


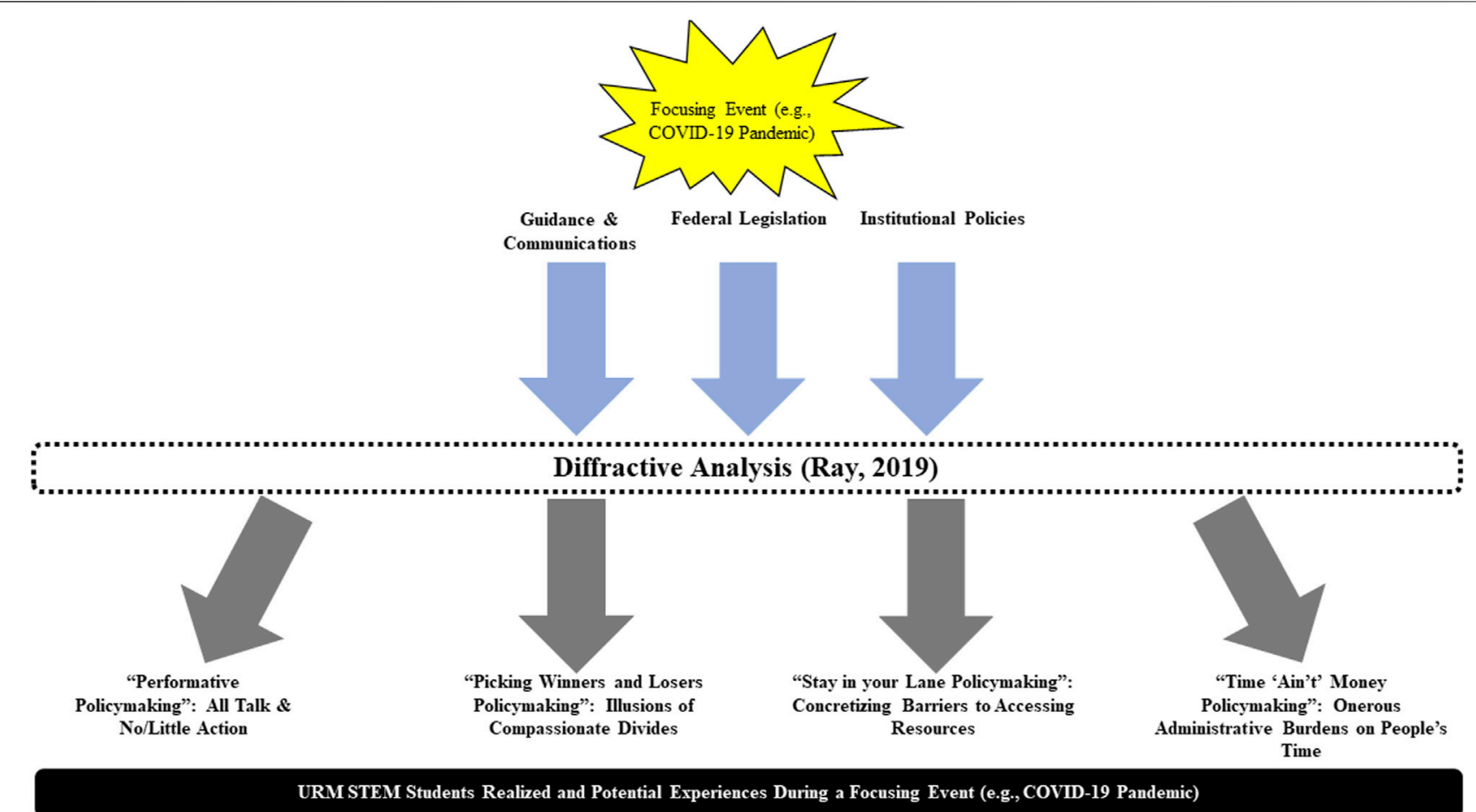

FIGURE 1 | Diagram of a Diffractive Reading of COVID-19 Policies and Communication Impact on URM STEM Students.

\section{Diffractive Analysis}

The specific method of critical policy analysis we employed is diffraction analysis. The concept of diffraction is borrowed from the physical sciences and used to describe the process of waves interacting with an obstacle (i.e., light waves diffracting through a prism to showcase different hues). Diffractive readings of policy then are primarily focused on differences and, most importantly, the effect of differences in the data produced through the analysis (Ulmer, 2016; Murris and Bozalek, 2019). Accordingly, the emergence of diffraction as a form of qualitative analysis posits that a more realistic and nuanced rendering of a phenomenon is possible when the researcher embraces a topic's complexity rather than seeking to reduce it to an essence (Ulmer, 2016; Murris and Bozalek, 2019). An increasing number of education studies have adopted this approach in various ways (Taguchi, 2012; Davies, 2014; Bodén, 2015).

\section{Positionality}

Murris and Bozalek (2019) assert that it is also vital to deconstruct "power-producing binaries. . .by being aware of who, or what, is included and excluded through the diffraction apparatus" (p. 1507). The data sources section below tackles the what, but in this section, we want to briefly overview who we are to meld "values and facts... together as part of one brew" (Murris and Bozalek, 2019, p. 1509).

The research team is made up of two people that identify as cis-heterosexual Black men (Authors 1 and 4) and two cisheterosexual women, one who identifies as White (Author 2) and the other as Hispanic (Authors 3 ). The team collectively has a range of experiences with STEM education, including one current STEM undergraduate student (Author 3) and another team member who has baccalaureate and graduate degrees in engineering (Author 4). Likewise, the team's experiences in policy range from previous work on Capitol Hill (Author 4) and in a Governor's office (Author 2) to no formal experience in policy (Authors 1 and 3). Our positioning relative to the ILLSAMP is also important to note as the entirety of the team contributes to various research projects that advance our understanding of the Alliance from different vantage points ranging from research volunteer to co-principal investigator.

The teams' collective and individual interest in these topics is shaped at a high level by an overarching concern for educational inequities, a belief in the importance of STEM as a mechanism for the uplift in minoritized communities, and a commitment to institutional change spurred by policy development and organizational transformation rooted in anti-deficit thinking (Harper, 2010). Consequently, we acknowledge and make explicit that our insights, identities, and experiences predated our engagement in this project and bind our analysis in a way that makes addressing inequities and student success the focal point.

\section{Data Sources}

We follow Ulmer's (2016) outline for enacting diffraction as a critical policy analysis method and highlight the full range of texts used in our study over the period of March 2020 to October 2020. Table 1 includes relevant characteristics for each of the institutions in the IL-LSAMP, which constitute the initial focus of our inquiry. From these institutions, our policy 
document ecosystem included; (a) The postsecondary education provisions of legislation passed by the US Congress to address and mitigate the effects of COVID-19; (b) policy and guidance statements from federal agencies related to allowable uses and intents of COVID-19-related funding; (c) policy statements from the Illinois state government and its agencies related to COVID19 regulations and resources; and (d) Institution and STEM department-specific COVID-19 policies at the 12 IL-LSAMP institutions (Chicago State University, n. d.) -including any downloadable messages to students and the broader university community.

In total, we collected 120 documents that formed the data set for this study. These documents were saved as PDF files and uploaded to Dedoose (qualitative data management tool) for data analysis. Table 2 provides representative examples of the types of documents and excerpts in our data set.

\section{Data Analysis}

Our central research question speaks to the ways pandemic policies and communications bolster the success of underrepresented minoritized students (URMs) majoring in STEM.

However, we noted both anecdotally and through the data collection process that few, if any, documents specifically addressed the success of students majoring in STEM. This also meant that it would be even less likely to find policies and communication during the early stages of the pandemic that addressed the intersection of URMs in STEM specifically.

Consequently, a diffractive analysis allows us to "read with the data" using theory (Ulmer, 2016; Murris and Bozalek, 2019), meaning we were able to focus on what was revealed in our data sources in light of how the data sources interacted with Ray's (2019) theory of racialized organizations and our multi-pronged diffractive analysis. Relying on a team approach to diffractive analysis allowed us to refract the policy documents through a racialized lens informed by our individual and collective interpretations.

\section{Analysis Procedures}

To enact this process, we first divided the 120 documents among the three team members and conducted a high-level overview of the policy documents in the context of Ray's (2019) theory to developed thematic codes. We then conducted multiple rounds of deductive coding-which produced 170 unique excerpts of text and participated in individual and group memoing. These steps yielded a total of 16 memos, which identify findings most responsive to our research question. Specifically, our dialogue led to identifying four considerations that illuminate patterns or potential patterns of racialized realities in how policies and communication strategies come together within organizations around student success in STEM.

\section{FINDINGS-DIFFRACTIVE READINGS: THE POTENTIALITIES OF POLICYMAKING FOR URM STEM STUDENT SUCCESS}

Our findings capture four main themes: (1) performative policymaking by institutions; (2) funding segregation; bolstering existing barriers to resources; and (4) insufficient time considerations. To present our collective analysis, we model the process of diffractive readings in the sections that follow. The format we utilize includes presenting an excerpt of Ray's (2019) theory of racialized organization and then an articulation of how various data sources entangle and disentangle with the excerpt to shed light on our orienting research question. Our overarching assertion is that the confluence of policymaking and communication amid a pandemic illuminates the potential role of organizations like LSAMP to leverage their existing positioning to facilitate enhanced URM STEM students' outcomes during focusing events.

\section{"Performative Policymaking": All Talk and No/Little Action}

Racialized organizations often decouple formal commitments to equity, access, and inclusion from policies and practices that reinforce, or at least do not challenge, existing racial hierarchies. (Ray, 2019, p. 42).

The all talk and no/little action finding exposes how organizations formally address inequality and racial disparity but, do not provide an action plan moving forward to target these inequities. This theme falls into Ray's (2019) description of racialized decoupling, as organizations often present themselves as "neutral" or "progressive" for initially highlighting the existence of racial disparities but do not adequately deal with the injustice taking place. This theme emerged from data analysis in several ways, including through state-level communication and higher education institutional response to the campus community.

For instance, the Governor's office in the State of Illinois began issuing proclamations focusing on the COVID-19 pandemic on March 12, 2020. On May 29, 2020, the Governor acknowledged that the COVID-19 virus had a disproportionate impact on the Hispanic and Black community, "...COVID-19 has claimed the lives of and continues to impact the health of Black and Hispanic Illinoisans at a disproportionately high rate-magnifying significant health disparities and inequities...”. This proclamation, as well as following proclamations, continued to recognize the racial disparity in the number of COVID-19 cases but did not provide an action plan on how to minimize the spread in these communities and better support them during the pandemic. Given the location of some of the IL-LSAMP institutions in locations with disproportionately high COVID19 positivity rates, this state-level inaction potentially creates additional burdens for students, faculty, and staff that reside in the surrounding geographic areas.

Yet, this entanglement of acknowledging the underlying pandemic-related issues, but not conveying specified plans, was present in various institutional responses (i.e., email communication) to students. One example includes a university moving to a pass-fail grading method in response to the hardship the pandemic has created for students. However, the university did not articulate how this new grading method would be rolled out, how students would be supported equitably in the 
TABLE 2 | Overview of data sources and representative examples.

Policy actor

Federal Government

Presidential Actions $(n=1)$

Congressional Legislation $(n=6)$

Federal Agencies

- Department of Defense $(n=1)$

- Department of Education ( $n=14)$

- Department of Energy $(n=1)$

- National Institutes for Health $(n=2)$

- National Science Foundation ( $n=6)$

Illinois Government

Department of Health ( $n=1)$

Illinois State Board of Education

( $\mathrm{n}=1$ )

Governor's Office ( $n=21$ )

IL-LSAMP Institutions

- Chicago State University $(\mathrm{n}=8)$

- DePaul University ( $\mathrm{n}=15)$

- Governors State University ( $n=1)$

- Illinois Institute of Technology $(\mathrm{n}=8)$

- Malcom X College $(n=6)$

- Morton College ( $n=11)$

- Northeastern Illinois University $(n=6)$

- Prairie State College $(n=1)$

- Saint Augustine College $(\mathrm{n}=0)$

- Southern Illinois University, Edwardsville ( $n=4)$

- University of Illinois, Chicago $(n=4)$

- University of Illinois, Springfield $(n=1)$
Example data sources

Coronavirus Aid, Relief, and Economic Security Act" or the

"CARES Act

\section{Example excerpt relevant}

to student success

SEC. 18004. (a) IN GENERAL - The Secretary shall allocate funding under this section as follows: (1) 90 percent to each institution of higher education to prevent, prepare for, and respond to coronavirus, by apportioning it - (A) 75 percent according to the relative share of full-time equivalent enrollment of Federal Pell Grant recipients who are not exclusively enrolled in distance education courses prior to the coronavirus emergency; and (B) 25 percent according to the relative share of fulltime equivalent enrollment of students who were not Federal Pell Grant recipients who are not exclusively enrolled in distance education courses prior to the coronavirus emergency

NSF Implementation of OMB Memorandum M-20-17, entitled, "Administrative Relief for Recipients and Applicants of Federal Financial Assistance Directly Impacted by the Novel Coronavirus (COVID-19) due to Loss of Operations" dated March 19, 2020

"As we face new and unique challenges in confronting the COVID19 epidemic, NSF is prioritizing the health and safety of the research community. NSF understands the effects this challenge will have on NSF-funded research and facilities, and we are committed to providing the greatest flexibilities to support your health and safety as well as your work. NSF is continually updating guidance and our online resources to keep you informed

Illinois CARES Act Fund Distribution for Higher Education Institutions

Illinois higher education institutions will receive \$429.7 million in funding under the CARES Act to help address the financial impact of COVID-19. Half of this funding, $\$ 214.9$ million, has been released to help provide assistance to students. The remaining funding goes to individual schools to cover refunds and loses related to the COVID-19 response. This is part of the $\$ 13.953$ billion provided for higher education under the CARES Act, section 18,004 Dear Students,

March 21, 2020: REMOTE/ONLINE CREDIT CLASSES As challenging as this week has been, we have witnessed tremendous resilience and dedication by you and all your fellow students. City Colleges faculty and staff have been working over the past week to be ready to resume courses this Monday, March 23. All credit courses except those listed here. . .] will resume with remote instruction. The entire City Colleges team is committed to your success, and we want to ensure that you are ready to complete your courses this term Please read this email carefully so you know what to expect transition, or options for students who needed letter grades (i.e., to increase their GPA score, applications). Another institution addressed safety concerns of their campus community, "Please be safe, while acknowledging that safety at times is a privilege not shared by all; be kind to others while standing up for truth and justice, and most of all be kind to yourselves." Although the university may appear to be progressive in acknowledging the racialized context of safety, they fail to provide resources for the students to be safe on and off-campus.

When it comes to the additional uncertainty URM students majoring in STEM might be navigating, these mixed messages might heighten tensions and concerns around staying on task and achieving the requisite technical skills, in a safe environment that will be expected of them to enter the labor force (Garibay, 2018; Lord et al., 2019). Diffracting these data through the theory illuminates how organizations, even with the best of intent, do not always adequately address the impact of their decisions or structures in place. When organizations acknowledge racial disparity but do not actively work to dismantle the oppressive structures that keep inequity in place, they fail to support those in their network in a meaningful way. Accordingly, this brings into view the role an Alliance might have played in advocating for follow-through and accountability on behalf of the communities 
and students who were being acknowledged, but potentially not supported, in accessible ways. In particular, Alliance leadership could consider ways to stay up to date with the messaging and actions each member institution is relaying in order to understand the context STEM students are navigating. A suggestion moving forward is not only to stay up to date on changes and communications at the institutional, state, and federal level, but also to follow up with the individual institutions who may not be providing inclusive and equitable support systems. This follow-up could be sharing research and best practices, concerns from students and staff, and ultimately call attention to the work that needs to be done.

\section{"Picking Winners and Losers Policymaking": Illusions of Compassionate Divides}

Within organizations, segregation or incorporation into the lower tires of organizational hierarchies diminishes one's ability to influence organizational procedures and the larger institutional environment (Ray, 2019, p. 36).

The Compassionate Divides dynamic focuses on how through educational policy, whether intentionally or not, separation of populations occurs within higher education. This separation can often limit peoples' access to resources based on their segregated group, create or maintain racial boundaries, and impose limitations on individual and collective influence on organizational change. This finding falls into Ray's (2019) description of segregation as an agency constraint of those in organizations. The funding available to higher education institutions through the CARES Act is based on enrollment classifications and numbers of students (i.e., full-time students, part-time students, Pell Grant-eligible students). This funding formula prioritizes full-time students over part-time, which in turn allocates more funding to schools with higher numbers of full-time students and less to those with higher part-time students. The parameters for allocation of funding through the CARES Act are critical to recognize because there are STEM students who are full-time, part-time, or Pell Grant recipients. Funding distribution based on rigid student classifications, like those identified previously, can disproportionately harm individuals in the segregated tiers that receive less money without sufficient consideration of actual financial need.

Funding segregation also occurred through federal agencies, like the National Institutes of Health (NIH), through the additional funding eligibility criteria: only those projects able to refocus on COVID-19 were eligible. In the absence of a complementary offer of technical assistance for such a task, or broader and more generous eligibility criteria, there remains a risk of this agency constraint limiting access to resources and limiting participation for vulnerable students. Understanding how STEM students, based on enrollment classifications, are being allocated more or less funding is necessary to identify how to support them with other resources (i.e., Alliance communication, state funding). Although this finding is represented the strongest in policy language and disbursement of COVID-19 related funding in a deficit manner, there are counterexamples of institutions addressing the disproportionate impact on segregated groups.

One institution changed its tuition costs to better support its part-time students during the pandemic. The change made students pay per course versus part-time students subsidizing the costs of full-time students taking more than 12 credit hours. The Illusion of Compassionate Divides finding further illustrates how "neutral" policies and institutional crisis responses can segregate populations and either assist them or limit their access to resources (i.e., funding). When creating policies, especially in times of crisis, the impact of segregation needs to be considered. The reality shaped by bringing the theory and text together spotlights a potential role for Alliances and similarSTEM education networks. For instance, Alliance leadership could have considered facilitating the sharing of best practices among member institutions on how to deal with the different ways the various policies were sorting students.

\section{"Stay in Your Lane Policymaking": Concretizing Barriers to Accessing Resources}

Segregated organizations maintain racial boundaries, channel resources, and help direct collective action. (Ray, 2019, p. 38).

The Barriers to Accessing Resources convergence highlights the responsibility and potential that institutions have been given to distribute resources to their students. This theme falls into Ray's (2019) description for legitimizing the unequal distribution of resources since the allocation of resources can lead to a reification of differential resources making it to underrepresented minorities. This dimension originates as a result of federal and state funding flowing from government coffers to schools and the resulting hierarchy of bureaucratic layers that place idiosyncratic restrictions on the use of funds. For example, the cover letter for the CARES Act requires that "of the amount allocated to each institution...at least 50 percent must be reserved to provide students with emergency financial aid grants...”. At the state level, for Illinois, authority over the distribution of funds is given to the schools, but there are restrictions on how students can receive the funds, stating "schools must use the student funding to provide cash supports directly to students through direct deposits into their accounts or through debit cards." Ray (2019) argues that racial hierarchies can enforce "passive participation" that produces racial inequality (p. 40), meaning that these well-intended policies based on governmental hierarchies, where racism is already entrenched, foster participation downstream in the policy implementation that does not fully remediate the initial racism embedded within the upstream policymaking process.

For instance, Illinois' policy described aboe narrowly prescribes to institutions how the funding has to be allocated to students creates or reinforces a barrier for students who might not be able to pick up a debit card or who do not have a valid or consistent mailing address to receive one. Further, the policy requires that students have a bank account in their name to receive the funds, which is not always possible. There is a growing 
body of research on the "under-banked and un-banked" within the United States economy, which demonstrates that those with less access to formal banking mechanisms tend to be younger and racial/ethnically minoritized (e.g., Long, 2020). Therefore, the barrier of being under-banked or un-banked is reinforced or concretized by the Illinois student funding policy.

Yet, in other ways, the policies give considerable latitude to institutions, as evidenced by the discretion institutions have in determining who to disburse funds. This means that each institution can determine criteria to ensure the funds be given to the students who need them most, but with other limitations. For example, Northeastern Illinois University sent an email on April 27, 2020, to students explaining that CARES Act funds would be distributed based on spring credit hours ( $\$ 42 /$ credit hour) with Pell grant eligible students received an additional \$15 per credit hour. Whereas Illinois Tech opted to use CARES Act funds to support students with unmet financial need in an April 28,2020 , email. Both approaches have merits and challenges that impact students in a range of ways-despite being wellintentioned. Understanding how broad policies and their implementation can limit the access to resources for URMs in STEM can help eliminate the unequal outcomes they cause. Yet, there did not exist an entity focused on translating the federal/ state or institution policies for their realities on STEM students in particular. Against this view, an Alliance's role could be to help students navigate the various processes and procedures set in place to access funds or receive support. Specifically, creating institutions specific guides for STEM students on how to receive support to alleviate confusion on processes that involve multiple steps and time. Additionally, identifying policies that are more systemic in nature (e.g., un-banked students) and advocating for flexibility or alternative to navigate around the issue, are actions Alliances might have considered.

\section{“Time Ain't' Money Policymaking": Onerous Administrative Burdens on People's Time}

For instance, people in the welfare system often experience time as daily management of permanent "crisis" given insufficient resources [...], and forced waiting is a "psychological cost" welfare bureaucrats impose on recipients to show their time has no value [...] (Ray, 2019, 37).

Our final diffractive engagement underscores the tension that colleges and universities, and broader institutions, dictate how time is spent within, or engaged with, the institution through their policies and administrative practices. Ray (2019) provides examples of onerous burdens the welfare state places on people that create obstacles and barriers and reinforce tropes that have disproportionate impacts on specific communities. Similarly, reading our texts through this portion of Ray's (2019) theory revealed that institutional decision-making impacted students' availability of time in numerous ways. For example, institutions tended to create temporal efficiencies that benefit the institutions, but create obstacles for students. Students were often left to decipher statements like "in the coming weeks" or "please check [Institution] site for details." An additional instance of this lack of clarity included directing students to web pages and emails for up to date communications without giving any time frames on how regularly updates would be provided. Taking this to its extreme could mean constantly updating the web page or checking email waiting for updates, which restricts the time of individuals with competing demands.

Another constraint on students' time involved requiring lowincome and under-resourced groups to expend additional resources to determine eligibility for means-tested programs. This came through in both communications to students (e.g., "the fund aims to provide eligible students facing short term, nonreoccurring financial emergencies with help in the form of grants that range from $\$ 100-\$ 500 ")$ and communications from federal agencies to institutions (i.e., "visit the Department to determine eligibility"). There are two consequences of this sort of policymaking and communication. First, it harkens the metaphor of the 'solvent-solute challenge,' which asks-are students incorporated into the institutions, or are institutions incorporated into students? Ray (2019) makes the case that a little of both is happening. On average, institutions are more capable (financially and organizationally) of serving students' needs than students are at attending to an institution's practices. Thus, placing burdens on students has a greater chance of harming students than reorganizing institutions or tapping into intermediary institutions like LSAMP to provide complementary support. Finally, time constraints assume an elevated Baseline. "Please continue to check webpage," presumes an elevated baseline of capacity from students and families. The insufficient or erroneous baseline being students have the basic resources with which to access the school's online resources, in a consistent and uninterrupted manner unlikely to interfere with their academic progress, which is not a reasonable assumption and therefore an unhelpful baseline. This is heightened amid a focusing event that is reorienting numerous touchpoints for individuals. Here again, Alliances are positioned to advocate for what students are experiencing to better guide interventions that aim to connect with these students. Specifically, this could look like an Alliance using their coordinators on each campus to streamline communication that includes specific details that alleviates any confusion or additional interpretation for students. Ultimately, an Alliance cannot assume that all institutional communications and actions are adequate, there is a need to be proactive versus reactive when it comes to supporting STEM students who are navigating a crisis.

\section{Implications for Policy, Practice, and Research}

The totality of our findings begins to make plain the numerous ways the policymaking and communication ecosystem perpetuate racialized harms in material and latent ways for students. We also noted the role LSAMP could play in ameliorating many of these concerns. These ancillary suggestions are not to second-guess the (in)actions of any particular Alliance or institutional leadership. We applaud many of the thoughtful, creative, and timely actions taken to support students in an unprecedented situation. Instead, the goal 
TABLE 3 | Matrix of stakeholder recommendations to support URM STEM student success amid a crisis.

\begin{tabular}{|c|c|c|c|c|}
\hline & Alliance Leadership & Institutional leadership & $\begin{array}{c}\text { Site Coordinators/STEM } \\
\text { faculty/Student } \\
\text { affairs Professionals }\end{array}$ & Policymakers \\
\hline Academic & $\begin{array}{l}\text { - Create or support the creation of } \\
\text { resources that share best } \\
\text { practices, train site coordinators } \\
\text { on the information and } \\
\text { disseminate to their campus }\end{array}$ & $\begin{array}{l}\text { Proactively create academic } \\
\text { policies for times of crisis } \\
\text { - Allow students the option to } \\
\text { choose pass/fail or letter grades } \\
\text { for their courses }\end{array}$ & $\begin{array}{l}\text { - Adjust academic requirements } \\
\text { (i.e., lessen the workload required } \\
\text { for courses) } \\
\text { - Share institutional resources that } \\
\text { can support students who need } \\
\text { assistance balancing school } \\
\text { (i.e., tutoring, writing center) } \\
\text { - Adjust the accessibility of } \\
\text { institutional resources (i.e., extend } \\
\text { tutoring hours, offer online tutoring) }\end{array}$ & \\
\hline Socioemotional & $\begin{array}{l}\text { - Follow up with institutional } \\
\text { leadership (i.e., provosts, } \\
\text { presidents) about campus } \\
\text { response frequently, share best } \\
\text { practices, share concerns of } \\
\text { STEM students and LSAMP } \\
\text { staff/faculty }\end{array}$ & $\begin{array}{l}\text { - Proactively create policies or } \\
\text { plans to address the wellbeing of } \\
\text { students on and off campus } \\
\text { - Minimize the steps expected of } \\
\text { students to take to access } \\
\text { resources }\end{array}$ & $\begin{array}{l}\text { - Advocate for transparent } \\
\text { communication that includes } \\
\text { specific steps to access needed } \\
\text { resources or processes, include } \\
\text { dates of deadlines or when } \\
\text { information will be updated } \\
\text { - Provide opportunities for students } \\
\text { to communicate their needs/ } \\
\text { concerns }\end{array}$ & $\begin{array}{l}\text { - Consider the workload required } \\
\text { of students in the creation of } \\
\text { policies (i.e., multiple steps to } \\
\text { apply for funding) }\end{array}$ \\
\hline Financial & $\begin{array}{l}\text { - Share best practices among } \\
\text { member institutions on how to } \\
\text { navigate how policies are sorting } \\
\text { students }\end{array}$ & $\begin{array}{l}\text { - Create institutional specific } \\
\text { guideline of how to receive } \\
\text { financial support that is detailed, } \\
\text { time specific and includes on } \\
\text { what date the information will be } \\
\text { updated }\end{array}$ & $\begin{array}{l}\text { - Create policies to allow student } \\
\text { workers to receive payment even if } \\
\text { not physically on campus due to a } \\
\text { crisis } \\
\text { - Follow up with STEM students } \\
\text { connected with the Alliance to } \\
\text { assist them in navigating receiving } \\
\text { financial support }\end{array}$ & $\begin{array}{l}\text { - Distribute funds more equitably } \\
\text { across student type (i.e., full-time, } \\
\text { part-time) } \\
\text { - Identify gaps in policies that } \\
\text { address the disbursement of } \\
\text { funding to students and allow for } \\
\text { institutions to address } \\
\text { accordingly (i.e., students who } \\
\text { do not have accounts in their } \\
\text { name or the ability to come to } \\
\text { campus to receive a debit card) } \\
\text { - Be in conversation before, } \\
\text { during, and after the crisis with } \\
\text { the Alliance to address how to } \\
\text { improve in the future/address } \\
\text { present concerns } \\
\text { - Approve follow-on supplemental } \\
\text { legislation and continue to } \\
\text { provide clear and unambiguous } \\
\text { guidance to local institutions on } \\
\text { allowable uses of funds and best } \\
\text { practices }\end{array}$ \\
\hline
\end{tabular}

of our analysis was to be imaginative in terms of what could have been done, as revealed through our diffractive reading of the texts. In the classic movie franchise, The Matrix, the rogue computer program, The Merovingian, opines that "choice is an illusion created between those with power and those without"-meaning that in any given situation the potential avenues of recourse are determined by those with relative power to set the parameters of the situation. We understand URM STEM students to be agentic, resourceful, and resilient (Harper, 2010; McGee, 2016) but recognize that their individual efforts are circumscribed by historical, policy, and organizational realities that do not always work in their favor. Therefore, our implications, summarized in Table 3, were developed in the spirit of being generative to enhance the STEM education community's ability to respond to the ongoing pandemic and prepare for future crises. Specifically, we focus on different stakeholders with varying dimensions of power that have some responsibility of dictating the realities that exist in the face of an educational crisis like the COVID-19 pandemic.

\section{LSAMP Alliances as Organizational Buffers}

Our initial contribution in terms of recommendations is encouraging Alliances to embrace what we call the role of Organizational Buffers during focusing events that have the likelihood of harming the URM STEM ecosystem. As Figure 2 depicts, Organizational Buffers position themselves between the potentialities of policies and communication and students. Similar to our diffractive reading of the texts, Organizational 




FIGURE 2 | Updated Diagram Reflecting the Potential Role of LSAMP as Organizational Buffers During Focusing Events.

Buffers filter policies and communications in ways that are cognizant of preexisting racialized realities and work within the resources and leadership existing in the Alliance to support students in complementary and supplementary ways. Specifically, this means sharing best practices early, and often, with fellow coordinators and institutional leaders in the Alliance, creating a controlled and coordinated space for rapid implementation, iteration, and improvement. For instance, quickly convening the governing board of the Alliance to brainstorm ways to support URM STEM students explicitly expands a function of an already existing structure in the LSAMP to be responsive to the realities of an emerging opportunity and threat. The remaining sections build on this metaphor of LSAMP as Organizational Buffers and highlight additional recommendations for policy, practice, and research targeted at different audiences.

\section{Leveraging Federal and State Government Leadership}

As we write, new, more virulent strains of the COVID-19 disease are spreading, the national vaccination operation is still ramping up, and Congress is locked in a partisan battle to pass a new round of relief funding for various sectors. Likewise, institutions are planning for the upcoming fall term amid declining resources and a cohort of recent graduates are entering into an uncertain labor market. While we cannot predict the future, we believe it is critical to start applying lessons learned from the immediate past as organizations begin to chart paths forward in ways that we hope are transformative and equity-minded, not just additive.

One obvious policy actor is the federal government, including Congress, the executive, and federal agencies. Based on insights from the findings, we note that Congress's legislative language and accompanying regulatory language from federal agencies should aim to streamline and collapse administrative procedures that reduce workload and, therefore, time to complete processes and gain access to valuable and often lifesaving resources. Also, government entities should prioritize authorizing policies not just for maximum flexibility, but provide proactive accountability metrics that center equity (McNair et al., 2019) and hold institutions-or direct funded bodies - to adhere to said practices.

\section{Institutional Interventions}

In terms of institutions, we suggest that various actions, such as crafting emergency policies, funding distributions, overall student support, and interaction with the federal government, should have two primary considerations. First, the broadest and most lenient definition of funding eligibility and resources to best accommodate local needs centered on equity should be adopted. Second, institutions must conduct proactive outreach to vulnerable subgroups likely to be disproportionately impacted by the pandemic. This is an area where LSAMP as Organizational Buffers can be consequential partners given the inroads and interventions they already have established with students. 


\section{Reimagining Research}

Finally, in terms of setting up a research agenda to build on this project, we encourage future studies to build on the concept of LSAMP as Organizational Buffers. Potential questions include what focusing events are LSAMP best positioned to engage; who within an Alliance's structure is best positioned to coordinate the activities of the Organizational Buffer; and how can LSAMP as Organizational Buffers be assessed. Another area for research is extending the intersection between STEM education and policy analysis concerned with students' racialized realities. Additional research in this area would yield a more remarkable ability to map students' intersectional realities that this paper did not engage with as substantively.

Furthermore, we assert that understanding initial actions and messaging in a crisis is critical in aiding how educators and researchers learn from the situation because of how these early efforts often set the baseline for future actions in a policy cycle (Kingdon, 2013). Building on this proposition though, we encourage future research to address other timeframes in this and other crises (e.g., mid-pandemic or post-election periods) both as standalone units and across time frames. In particular, we suggest future researchers consider ways to analyze how messaging and policies shifted, changed, or stayed the same based on timeframe and the realities of the crisis. Finally, case study research that gathers insights into stakeholders impacted by the policymaking process and that receive organizational communication could yield insights into the policy implementation process as experienced by people within different but related contexts. By seeding new intellectual avenues and encouraging policymaking and communications that foreground equity, LSAMP have the potential to be better positioned to support URM STEM student success during the net local, national, or global issue.

\section{REFERENCES}

Anderson, K. J. B. (2012). Science Education and Test-Based Accountability: Reviewing Their Relationship and Exploring Implications for Future Policy. Sci. Ed. 96 (1), 104-129. doi:10.1002/sce.20464

Apple, M. W. (2019). On Doing Critical Policy Analysis. Educ. Pol. 33 (1), 276-287. doi:10.1177/0895904818807307

Baber, L. D., and Jackson, J. (2018). From the Edge of success to the center. Development of LSAMP alliances, 1987-2017. Available at: http://www.iinspirelsamp.org/wpcontent/uploads/2016/11/Quantitative-Research-Brief_2018.pdf.

Bensimon, E. M., Dowd, A. C., Stanton-Salazar, R., and Dávila, B. A. (2019). The Role of Institutional Agents in Providing Institutional Support to Latinx Students in STEM. Rev. Higher Edu. 42 (4), 1689-1721. doi:10.1353/rhe.2019.0080

Birkland, T. A. (1998). Focusing Events, Mobilization, and Agenda Setting. J. Pub. Pol. 18 (1), 53-74. Available at: https://www.jstor.org/stable/4007601. doi:10.1017/s0143814x98000038

Bodén, L. (2015). The Presence of School Absenteeism. Cult. Stud. $\leftrightarrow$ Crit. Methodologies 15 (3), 192-202. doi:10.1177/1532708614557325

Bolsen, T., and Druckman, J. N. (2018). Do partisanship and Politicization Undermine the Impact of a Scientific Consensus Message about Climate Change?. Group Process. Intergroup Relat. 21 (3), 389-402. doi:10.1177/1368430217737855

Bullock, E. (2017). Only STEM Can Save Us? Examining Race, Place, and Stem Education as Property. Educ. Stud. 53 (6), 628-641. doi:10.1080/ 00131946.2017 .1369082

\section{DATA AVAILABILITY STATEMENT}

Publicly available datasets were analyzed in this study. This data can be found here: https://www.openicpsr.org/openicpsr/project/ 132401/version/V1/view.

\section{AUTHOR CONTRIBUTIONS}

$\mathrm{DM}$ and $\mathrm{KD}$ contributed to the conception, design, and initial proposal of the study. DM, VC, and MA collected all the data and DM uploaded them to the data analysis software. All authors participated in at least two of the three data analysis phases. All authors wrote initial drafts of various sections of the manuscript. DM wrote drafts of the introduction, theoretical framework, and research design. VC wrote a draft of the literature review. VC, MA, and $\mathrm{KD}$ wrote the first draft of the findings. KD wrote a draft of the implications and conclusion. All authors contributed to editing the manuscript, with DM coordinating subsequent revisions. All authors have read and approved the submitted version.

\section{FUNDING}

This material is based upon the work supported by the National Science Foundation under grant no. 1911341.

\section{ACKNOWLEDGMENTS}

The authors would like to thank Norma Lopez for providing helpful comments on earlier drafts of the manuscript. The authors would also like to thank members and leaders of the Illinois LSAMP for their cooperation during this project.

Burt, B. A., Stone, B. D., Motshubi, R., and Baber, L. D. (2020). STEM Validation Among Underrepresented Students: Leveraging Insights from a STEM Diversity Program to Broaden Participation. J. Divers. Higher Edu. doi: $10.1037 /$ dhe0000300

Cabrera, N. L. (2014). Exposing Whiteness in Higher Education: White Male College Students Minimizing Racism, Claiming Victimization, and Recreating white Supremacy. Race Ethn. Edu. 17 (1), 30-55. doi:10.1080/ 13613324.2012.725040

Clewell, B. C., Cosentino de Cohen, C., Deterding, N., and Tsui, L. (2006). Final Report on the Evaluation of the National Science Foundation Louis Stokes Alliances for Minority Participation Program. Available at: https://www.urban. org/research/publication/final-report-evaluation-national-science-foundationlouis-stokes-alliances-minority-participation-program. doi:10.1037/ e723012011-001

Collier, D., Fitzpatrick, D., Dell, M., Snideman, S., Marsicano, C., and Kelchen, R. (2021). We Want You Back: Uncovering the Influences on In-Person Instructional Operations in Fall 2020. SSRN J. doi:10.2139/ssrn.3778772

Collier, D., Fitzpatrick, D., Snideman, S., and Marsicano, C. R. (2020). "What'd We Miss?": An Initial Analysis of Politics, Demographics, and COVID-19 Rates in Colleges' Resumption of Instructional Operations for Fall 2020. doi:10.33774/ apsa-2020-4c0f2

Cox, M., London, J., Ahn, B., Williams, P., and McGhee, C. (2012). "LSAMP Indiana: Lessons Learned from a Diversity Program Serving Underrepresented Minority Students," in ASEE Annual Conference and Exposition, Conference Proceedings. doi:10.18260/1-2-21665 
Davies, B. (2014). Reading Anger in Early Childhood Intra-actions. Qual. Inq. 20 (6), 734-741. doi:10.1177/1077800414530256

DeMatthews, D., Knight, D., Reyes, P., Benedict, A., and Callahan, R. (2020). From the Field: Education Research during a Pandemic. Educ. Res. 49 (6), 398-402. doi:10.3102/0013189X20938761

Dewsbury, B. M. (2020). Deep Teaching in a College STEM Classroom. Cult. Stud. Sci. Educ. 15 (1), 169-191. doi:10.1007/s11422-018-9891-z

Diem, S., Young, M. D., Welton, A. D., Mansfield, K. C., and Lee, P. L. (2014). The Intellectual Landscape of Critical Policy Analysis. Int. J. Qual. Stud. Edu. 27 (9), 1068-1090. doi:10.1080/09518398.2014.916007

Doerschuk, P., Bahrim, C., Daniel, J., Kruger, J., Mann, J., and Martin, C. (2016). Closing the Gaps and Filling the Stem Pipeline: A Multidisciplinary Approach. J. Sci. Educ. Technol. 25 (4), 682-695. doi:10.1007/s10956-016-9622-8

Faehnrich, B., and Ruser, A. (2019). 'Operator, Please' - Connecting Truth and Power at the Science-Policy Interface. Jcom 18 (03). doi:10.22323/2.18030501

Fischhoff, B., and Scheufele, D. A. (2014). "The Science of Science Communication II. IProc. Natl. Acad. Sci. 111. National Academy of Sciences, 13583-13584. doi:10.1073/pnas.1414635111

Fortuna, L. R., Tolou-Shams, M., Robles-Ramamurthy, B., and Porche, M. V. (2020). Inequity and the Disproportionate Impact of COVID-19 on Communities of Color in the United States: The Need for a TraumaInformed Social justice Response. Psychol. Trauma Theor. Res. Pract. Pol. 12 (5), 443-445. doi:10.1037/tra0000889

Gándara, D. (2020). How the Sausage Is Made: An Examination of a State Funding Model Design Process. J. Higher Edu. 91 (2), 192-221. doi:10.1080/ 00221546.2019 .1618782

Garibay, J. C. (2018). Beyond Traditional Measures of STEM Success: Long-Term Predictors of Social Agency and Conducting Research for Social Change. Res. High Educ. 59 (3), 349-381. doi:10.1007/s11162-017-9470-2

Gehrke, S., and Kezar, A. (2017). The Roles of STEM Faculty Communities of Practice in Institutional and Departmental Reform in Higher Education. Am. Educ. Res. J. 54 (5), 803-833. doi:10.3102/0002831217706736

Gillborn, B. D. (2005). Education Policy as an Act of white Supremacy: Whiteness, Critical Race Theory and Education Reform. J. Edu. Pol. 20 (4), 485-505. doi:10.1080/02680930500132346

Glasener, K. M., Martell, C. A., and Posselt, J. R. (2019). Framing Diversity: Examining the Place of Race in Institutional Policy and Practice postaffirmative Action. J. Divers. Higher Edu. 12 (1), 3-16. doi:10.1037/dhe0000086

Glennie, E., Mason, M., Dalton, B., and Edmunds, J. (2019). Preparing Students for STEM College and Careers: The Influence of Redesigned High Schools in North Carolina. High Sch. J. 102 (3), 228-257. doi:10.1353/hsj.2019.0008

González Canché, M. S. (2018). Geographical Network Analysis and Spatial Econometrics as Tools to Enhance Our Understanding of Student Migration Patterns and Benefits in the U.S. Higher Education Network. Rev. Higher Edu. 41 (2), 169-216. doi:10.1353/rhe.2018.0001

Goodwin, S. A., and Mitchneck, B. (2020). Ensuring the Pandemic Doesn't Negatively Impact Women in STEM, Especially Those of Color (Opinion). Inside. Higher. ed. Available at: https://www.insidehighered.com/views/2020/ 05/13/ensuring-pandemic-doesnt-negatively-impact-women-stem-especially-thosecolor. doi:10.23912/9781911635574-4440

Graham, J. M., Caso, R., Rierson, J., and Jong-Hwan Lee, J. H. (2002). The Impact of the Texas LSAMP Program on Under-represented Minority Students at Texas A \& M University's College of Engineering: a Multi-Dimensional Longitudinal Study. Proc. - Front. Edu. Conf. 2. doi:10.1109/fie.2002.1158218

Gruber, J., and Johnson, S. (2019). Jump-starting America: How Breakthrough Science Can Revive Economic Growth and the American Dream. Hachette Book Group.

Harper, S. R. (2010). An Anti-deficit Achievement Framework for Research on Students of Color in STEM. New Dir. Institutional Res. 2010 (148), 63-74. doi:10.1002/ir.362

Harper, S. R., Patton, L. D., and Wooden, O. S. (2009). Access and Equity for African American Students in Higher Education: A Critical Race Historical Analysis of Policy Efforts. J. Higher Edu. 80 (4), 389-414. doi:10.1080/ 00221546.2009.11779022

Harper, S. R. (2012). Race without Racism: How Higher Education Researchers Minimize Racist Institutional Norms. Rev. Higher Edu. 36 (1), 9-29. doi:10.1353/rhe.2012.0047

Harris, C. I. (1993). Whiteness as Property. Harv. L. Rev. 106 (8), 1707-1790. doi: $10.2307 / 1341787$
Harris, J. C., and Patton, L. D. (2018). Un/Doing Intersectionality through Higher Education Research. J. Higher Edu. 90, 347-372. doi:10.1080/ 00221546.2018 .1536936

Haynes, C., and Patton, L. D. (2019). From Racial Resistance to Racial Consciousness: Engaging white STEM Faculty in Pedagogical Transformation. J. Cases Educ. Leadersh. 22 (2), 85-98. doi:10.1177/1555458919829845

Henderson, C., Beach, A., and Finkelstein, N. (2011). Facilitating Change in Undergraduate STEM Instructional Practices: An Analytic Review of the Literature. J. Res. Sci. Teach. 48 (8), 952-984. doi:10.1002/tea.20439

Hill, L. B. (2020). Understanding the Impact of a Multi-Institutional Stem Reform Network through Key Boundary-Spanning Individuals. J. Higher Edu. 91 (3), 455-482. doi:10.1080/00221546.2019.1650581

Hillman, N. W. (2016). Geography of College Opportunity. Am. Educ. Res. J. 53 (4), 987-1021. doi:10.3102/0002831216653204

Hillman, N. W., Tandberg, D. A., and Sponsler, B. A. (2015). Public Policy and Higher Education: Strategies for Framing a Research Agenda. ASHE High. Edu. Rept. 41 (2), 1-98. doi:10.1002/aehe.20020

Honig, M. I. (2004). The New Middle Management: Intermediary Organizations in Education Policy Implementation. Educ. Eval. Pol. Anal. 26 (1), 65-87. doi:10.3102/01623737026001065

Hurtado, S., Cuellar, M., and Guillermo-Wann, C. (2011). Quantitative Measures of Students' Sense of Validation: Advancing the Study of Diverse Learning Environments. Enrollment Mangement J. 5 (2), 53-71.

Ireland, D. T., Freeman, K. E., Winston-Proctor, C. E., DeLaine, K. D., McDonald Lowe, S., and Woodson, K. M. (2018). (Un)hidden Figures: A Synthesis of Research Examining the Intersectional Experiences of Black Women and Girls in Stem Education. Rev. Res. Edu. 42 (1), 226-254. doi:10.3102/ $0091732 X 18759072$

Johnson, J., and Howley, C. B. (2015). Contemporary Federal Education Policy and Rural Schools: A Critical Policy Analysis. Peabody J. Edu. 90 (2), 224-241. doi:10.1080/0161956X.2015.1022112

Jones, T., Jones, S., Elliott, K. C., Russell Owens, L., Assalone, A. E., and Gándara, D. (2017). "Policy Actors, Advocates, and Critics: The Promotion and Critique of Performance and Outcomes-Based Funding's Impact on Equity," in Outcomes Based Funding and Race in Higher Education. Springer International Publishing, 107-121. doi:10.1007/978-3-319-49436-4_6

Kennedy, A. (2019). The Politics of Skilled Immigration: Explaining the Ups and downs of the US H-1B Visa Program. Int. Migration Rev. 53 (2), 346-370. doi:10.1177/0197918318769312

Kezar, A. J., and Holcombe, E. M. (2019). Leveraging Multiple Theories of Change to Promote Reform: An Examination of the AAU STEM Initiative. Educ. Pol.. doi:10.1177/0895904819843594

Kezar, A. (2011). What Is the Best Way to Achieve Broader Reach of Improved Practices in Higher Education?. Innov. High Educ. 36 (4), 235-247. doi:10.1007/ s10755-011-9174-z

King, B., Thurston, L., Montelone, B., and Paula, A. (2016). Mixed Method Study of Impact of KS-LSAMP Summer Research Experiences on STEM Students from Underrepresented Groups. Institute for Student Learning Assessment. Available at: https://newprairiepress.org/isla/conference/2016/3. doi:10.1109/ educon.2016.7474661

Kingdon, J. W. (2013). Agendas, Alternatives, and Public Policies. 3rd ed. Pearson.

Kushner Gadarian, S., Goodman, S. W., and Pepinsky, T. B. (2020). Partisanship, Health Behavior, and Policy Attitudes in the Early Stages of the COVID-19 Pandemic. SSRN J. doi:10.2139/ssrn.3562796

LePeau, L. A., Hurtado, S. S., and Williams, L. (2019). Institutionalizing Diversity Agendas: Presidents' Councils for Diversity as Mechanisms for Strategic Change. J. Student Aff. Res. Pract. 56 (2), 123-137. doi:10.1080/ 19496591.2018.1490306

LePeau, L. A., Morgan, D. L., Zimmerman, H. B., Snipes, J. T., and Marcotte, B. A. (2016). Connecting to Get Things Done: A Conceptual Model of the Process Used to Respond to Bias Incidents. J. Divers. Higher Edu. 9 (2), 113-129. doi:10.1037/a0039509

Long, M. G. (2020). Informal Borrowers and Financial Exclusion: The Invisible Unbanked at the Intersections of Race and Gender. The Rev. Black Polit. Economy 47 (4), 363-403. doi:10.1177/0034644620938620

Lord, S. M., Ohland, M. W., Layton, R. A., and Camacho, M. M. (2019). Beyond Pipeline and Pathways: Ecosystem Metrics. J. Eng. Educ. 108 (1), 32-56. doi:10.1002/jee. 20250 
Madkins, T., and Nasir, N. i. (2019). "Building on Students' Cultural Practices in STEM," in Language and Cultural Practices in Communities and Schools: Bridging Learning for Students from Non-dominant Groups. Editors I. M. García-Sánchez and M. F. Orellana (Routledge), 59-75. doi:10.4324/ 9780429486708-4

Mansfield, K. C., Welton, A. D., and Grogan, M. (2014). "Truth or consequences": A Feminist Critical Policy Analysis of the STEM Crisis. Int. J. Qual. Stud. Edu. 27 (9), 1155-1182. doi:10.1080/09518398.2014.916006

Marsicano, C., Felten, K., Toledo, L., and Buitendorp, M. (2020). Tracking Campus Responses to the COVID-19 Pandemic. doi:10.33774/APSA-2020-3WVRL

McCormick, G. (2021). The COVID-19 Pandemic Affects All College Students, but Probably Not Equally | Penn State University. Available at: https://news.psu. edu/story/620290/2020/05/18/research/covid-19-pandemic-affects-all-collegestudents-probably-not-equally

McCoy, D. L., Luedke, C. L., and Winkle-Wagner, R. (2017). Encouraged or Weeded Out: Perspectives of Students of Color in the STEM Disciplines on Faculty Interactions. J. Coll. Student Dev. 58 (5), 657-673. doi:10.1353/ csd.2017.0052

McGee, E. (2018). "Black Genius, Asian Fail": The Detriment of Stereotype Lift and Stereotype Threat in High-Achieving Asian and Black STEM Students. AERA Open. 4 (4). doi:10.1177/2332858418816658

McGee, E. O. (2016). Devalued Black and Latino Racial Identities. Am. Educ. Res. J. 53 (6), 1626-1662. doi:10.3102/0002831216676572

McNair, T. B., Bensimon, E. M., and Malcom-Piqueux, L. (2019). From Equity Talk to Equity Walk: Expanding Practitioner Knowledge for Racial justice in Higher Education. John Wiley \& Sons.

Means, B., Wang, H., Wei, X., Iwatani, E., and Peters, V. (2018). Broadening Participation in Stem College Majors: Effects of Attending a STEM-Focused High School. AERA Open. 4 (4). doi:10.1177/2332858418806305

Morales-Doyle, D., Gutstein, E. R., and ", Rico. (2019). Racial Capitalism and STEM Education in Chicago Public Schools. Race Ethn. Edu. 22 (4), 525-544. doi:10.1080/13613324.2019.1592840

Murris, K., and Bozalek, V. (2019). Diffracting Diffractive Readings of Texts as Methodology: Some Propositions. Educ. Philos. Theor. 51 (14), 1504-1517. doi:10.1080/00131857.2019.1570843

National Science Foundation. Louis Stokes Alliances for Minority Participation (LSAMP). Available at: https://www.nsf.gov/pubs/2017/nsf17579/nsf17579.pdf.

Nature Editorial Board (2020). Why Nature Needs to Cover Politics Now More Than Ever. NatureNature Res. 586, 169-170. doi:10.1038/d41586-020-02797-1

Ness, E. C. (2010). "The Role of Information in the Policy Process: Implications for the Examination of Research Utilization in Higher Education Policy," Higher Education: Handbook of Theory and Research. Editor J. Smart (Dordrecht: Springer) 25, 1-49. doi:10.1007/978-90-481-8598-6_1

Norris, P., and Inglehart, R. (2009). Cosmopolitan Communications: Cultural Diversity in a Globalized World. Cambridge University Press. doi:10.1017/ cbo9780511804557

Ong, M., Smith, J. M., and Ko, L. T. (2018). Counterspaces for Women of Color in STEM Higher Education: Marginal and central Spaces for Persistence and success. J. Res. Sci. Teach. 55 (2), 206-245. doi:10.1002/tea.21417

Ong, M., Wright, C., Espinosa, L., and Orfield, G. (2011). Inside the Double Bind: A Synthesis of Empirical Research on Undergraduate and Graduate Women of Color in Science, Technology, Engineering, and Mathematics. Harv. Educ. Rev. 81 (2), 172-209. doi:10.17763/haer.81.2.t022245n7x4752v2

Orrenius, P. M., and Zavodny, M. (2015). Does Immigration Affect whether US Natives Major in Science and Engineering?. J. Labor Econ. 33 (S1), S79-S108. doi:10.1086/676660

Owen, D. S. (2007). Towards a Critical Theory of Whiteness. Philos. Soc. Criticism 33 (2), 203-222. doi:10.1177/0191453707074139

Park, J. J., Kim, Y. K., Salazar, C., and Hayes, S. (2020). Student-Faculty Interaction and Discrimination from Faculty in STEM: The Link with Retention. Res. High Educ. 61 (3), 330-356. doi:10.1007/s11162-019-09564-w

Porter, A. L., Roessner, J. D., Oliver, S., and Johnson, D. (2006). A Systems Model of Innovation Processes in university STEM Education. J. Eng. Edu. 95 (1), 13-24. doi:10.1002/j.2168-9830.2006.tb00874.x

Rall, R. M., Morgan, D. L., and Commodore, F. (2020). Toward Culturally Sustaining Governance in Higher Education: Best Practices of Theory, Research, and Practice. J. Edu. Hum. Resour. 38 (1), 139-164. doi:10.3138/ jehr.2019-0006
Ray, V. (2019). A Theory of Racialized Organizations. Am. Sociol. Rev. 84 (1), 26-53. doi:10.1177/0003122418822335

Reinholz, D. L., and Apkarian, N. (2018). Four Frames for Systemic Change in STEM Departments. IJ STEM Ed. 5. Springer. doi:10.1186/s40594-0180103-x

Roberts, M. R. (2009). Realizing Societal Benefit from Academic Research: Analysis of the National Science Foundation's Broader Impacts Criterion. Social Epistemol. 23 (3-4), 199-219. doi:10.1080/02691720903364035

Spillane, J. P., and Callahan, K. A. (2000). Implementing State Standards for Science Education: What District Policy Makers Make of the Hoopla. J. Res. Sci. Teach. 37 (5), 401-425. doi:10.1002/(sici)1098-2736(200005)37:5<401::aidtea2 $>3.0 . c 0 ; 2-\mathrm{d}$

Stewart, D.-L., and Nicolazzo, Z. (2018). High Impact of [whiteness] on Trans ${ }^{\star}$ Students in Postsecondary Education. Equity Excell. Edu. 51 (2), 132-145. doi:10.1080/10665684.2018.1496046

Taguchi, H. L. (2012). A Diffractive and Deleuzian Approach to Analysing Interview Data. Feminist Theor. 13 (3), 265-281. doi:10.1177/ 1464700112456001

The National Academies of Science Engineering Medicine (2017). Building America's Skilled Technical Workforce. National Academies Press. doi: $10.17226 / 23472$

The White House (2021). Fact Sheet: President Biden Takes Executive Actions to Tackle the Climate Crisis at home and Abroad, Create Jobs, and Restore Scientific Integrity across Federal Government. Available at: https://www.whitehouse.gov/ briefing-room/statements-releases/2021/01/27/fact-sheet-president-biden-takesexecutive-actions-to-tackle-the-climate-crisis-at-home-and-abroad-create-jobsand-restore-scientific-integrity-across-federal-government/.

Tichavakunda, A. A. (2020). Studying Black Student Life on Campus: Toward a Theory of Black Placemaking in Higher Education. Urban Edu... doi:10.1177/ 0042085920971354

Twine, F. W. (2018). Technology's Invisible Women: Black Geek Girls in Silicon Valley and the Failure of Diversity Initiatives. Int. J. Crit. Divers. Stud. 1 (1), 58. doi:10.13169/intecritdivestud.1.1.0058

Ulmer, J. B. (2016). Diffraction as a Method of Critical Policy Analysis. Educ. Philos. Theor. 48 (13), 1381-1394. doi:10.1080/00131857.2016.1211001

Whatley, M., and Castiello-Gutiérrez, S. (2021). Balancing Finances, Politics, and Public Health: International Student Enrollment and Reopening Plans at Us Higher Education Institutions amid the COVID-19 Pandemic. Available at: https://collegecrisis.org/wp-content/uploads/2021/02/C2i WP_210201.pdf.

Wolfmeyer, M., Lupinacci, J., and Chesky, N. (2017). Three Ontologies of STEM Education: An Apolitical Curricular Trend, Eurocentric Economic Policy, and Discursive Episteme. Crit. Edu. 8 (15), 68-81. Available at: http://ojs.library. ubc.ca/index.php/criticaled/article/view/186337.

Woolston, C. (2020). 'It's like We're Going Back 30 years': How the Coronavirus Is Gutting Diversity in Science. Nature. doi:10.1038/d41586-020-02288-3

Young, M. D., and Diem, S. (2018). "Doing Critical Policy Analysis in Education Research: An Emerging Paradigm," in Complementary Research Methods for Educational Leadership and Policy Studies. Palgrave Macmillan, 79-98. doi:10.1007/978-3-319-93539-3_5

Conflict of Interest: The authors declare that the research was conducted in the absence of any commercial or financial relationships that could be construed as a potential conflict of interest.

Publisher's Note: All claims expressed in this article are solely those of the authors and do not necessarily represent those of their affiliated organizations, or those of the publisher, the editors and the reviewers. Any product that may be evaluated in this article, or claim that may be made by its manufacturer, is not guaranteed or endorsed by the publisher.

Copyright $\odot 2021$ Morgan, Callais, Acevedo and Davis. This is an open-access article distributed under the terms of the Creative Commons Attribution License (CC BY). The use, distribution or reproduction in other forums is permitted, provided the original author(s) and the copyright owner(s) are credited and that the original publication in this journal is cited, in accordance with accepted academic practice. No use, distribution or reproduction is permitted which does not comply with these terms. 